\title{
Analysis of the seismic data associated with the receiver's interval in seismic acquisitions in Parnaíba Basin
}

Enéas Macêdo dos Santos Neto*1, Sandro Ferreira Miranda ${ }^{1}$, Carlos Eduardo Siedschlag ${ }^{1}$, Diogo Michelon ${ }^{1}$, Frederico Silveira de Miranda ${ }^{1}$, Roberto Baldanza Ribeiro ${ }^{1}$, João Luiz Caldeira ${ }^{1}$, Heron Schots ${ }^{2},{ }^{1}$ ENEVA S.A and ${ }^{2}$ CPGEO

Copyright 2021, SBGf - Sociedade Brasileira de Geofísica

This paper was prepared for presentation during the $17^{\text {th }}$ International Congress of the Brazilian Geophysical Society held in Rio de Janeiro, Brazil, 16-19 August 2021.

Contents of this paper were reviewed by the Technical Committee of the $17^{\text {th }}$ International Congress of the Brazilian Geophysical Society and do not necessarily represent any position of the SBGf, its officers or members. Electronic reproduction or storage of any part of this paper for commercial purposes without the written consent of the Brazilian Geophysical Society is prohibited.

\section{Abstract}

The onshore seismic acquisition activity has undergone a major technological advance in recent years, with the development of new recording equipment and the availability of receivers, whether geophones or high sensitivity accelerometers, which enables improvements on the logistics of the operation, enabling record of a wider range of frequencies, resulting in better quality of the data.

Obtaining a good subsurface imaging quality is always a challenging task. In addition to the difficulties of operational logistics, such as people and equipment movimentation, there are the adversities imposed by the environmental and geographical conditions of the study area, related to the variations of relief, to the rainy season, to lithostratigraphy with the igneous rocks outcropping and to the interference of human (social, economic and cultural) activities.

The present work, carried out in the Parnaíba Basin, aims to demonstrate a case study performed with the registration of $2 \mathrm{D}$ seismic data from three seismic lines, acquired with explosive source and the interval between receiving stations (IRS) reduced by half, doubling the number of active channels on the same split spread array. All other acquisition parameters remained the same.

\section{Introduction}

In 2004, the National Organization of the Petroleum Industry (ONIP) and the National Observatory (ON), through the ONIP / GEO Project, in the publication of the book Situation of Terrestrial Seismic in Brazil, point out that "[...] most of the Brazilian onshore sedimentary basins presents scarcity of seismic coverings for oil exploration "(ONIP, 2004, p.64) and adds that the Parnaíba Basin is among the four major Paleozoic basins (Solimões, Amazonas, Parnaíba and Paraná) the one that presents the fewer coverage of seismic lines.

By the end of 2009, with the exploratory blocks offering in the 9th Bidding Round from the National Agency of Petroleum, Natural Gas and Biofuels (ANP), there was a drastic change in the exploration scenario of natural gas in the Parnaiba basin, resulting on the discovery of the producing fields of the Hawks Park. According to Araújo $(2017$, p. 3) "the Parnaíba Basin emerges today as the 2nd largest onshore gas producer and accounts for approximately $7 \%$ of the production of natural gas in Brazil".

In this scenario, the performance of the company Eneva, "the largest private natural gas operator in the country" (ENEVA, 2021), which has already invested significant financial resources in E\&P (Exploration and Production) in the Parnaíba basin, stands out.

As stated by Michelon et al. (2020, p. 28) in a technical article published by the Brazilian Geophysical Society (SBGf) "The interpretation of seismic data has been, in this basin, the most effective methodology in the search for opportunities [...]. A major challenge is to acquire seismic data with sufficient quality to minimize uncertainties [...]".

According to Santos (2018, p. 23) "The seismic data acquisition is the first step in the exploratory chain and aims to provide quality data so that higher resolution images can be obtained and more accurately infer the subsurface properties, minimizing exploratory risk and financial, operational and environmental costs. The interpretation of seismic data, by geophysicists and / or geologists, favors the determination of the location for drilling the exploratory well, the next stage of the prospecting process, contributing to minimize the risks of decision making.

According to Ancelme $(2015$, p. 8 ) "The subsoil is generally composed of different layers of sediments". Different geological layers are characterized by having different physical properties, including different acoustic impedances. This characteristic is the basis of the data acquisition process known as Reflection Seismic".

The most important 2D seismic acquisition parameters are the Interval between Receiving Stations (IRS), the Number of Active Channels in the recording device (NC) and the Shot Point Interval (SPI). The IRS must be defined to obtain the correct sampling of the signal and also of the coherent noise, without alias and in consonance with the desired resolution (SANTOS, 2018, p. 24-26).

Eneva's exploratory success in the Parnaiba basin is due, among other factors, to the numerous parameter and equipment tests carried out during the four major seismic campaigns, since 2009, which enabled the reduction of acquisition costs and the significant advance of the quality of the processed data. Most of the tests performed, were done in one campaign, analyzed and then applied on the next campaign. The figure 1, shows evolution of parameters of ENEVA during seismic campaigns (20092018), where many types of sensors, different dynamite weights, different dynamite burial depth and different intervals were used. 
As mentioned by Miranda, head of exploration at ENEVA, in (AAPG, 2021, p.12) work in the Parnaíba's Paleozoic setting provides an exciting opportunity to take on both geological and technological challenges. "During our 10year history we have aimed our exploration targets in Paleozoic basins that were previously not so promising, due to complex geology and/or logistics.

ENEVA has been investing massively in the survey of seismic data, since 2009, more than 25,000 km (twentyfive thousand kilometers) of $2 \mathrm{D}$ seismic lines have been acquired, in addition to $470 \mathrm{~km}^{2}$ (four hundred and seventy square kilometers) of $3 D$ seismic data. All these efforts have contributed to ENEVA being now established in the Brazilian private sector using an integrated business concept that extends from gas exploration to power generation, known as Reservoir to Wire (R2W).

\begin{tabular}{|c|c|c|c|}
\hline \multirow[b]{2}{*}{2009} & $4000-25-0-25-4000$ & $\vec{P}, \frac{S G-10}{t+}, \vec{a}$ & न SP \\
\hline & $2500-25-0-25-2500$ & $\vec{P}+\frac{\mathrm{SG}-10}{T_{\mathrm{sn}}+T^{2}}$ & 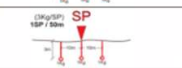 \\
\hline 2012 & $2500-25-0-25-2500$ & P., $\frac{\text { SG-10 }}{T_{20}^{T},+2}$ & $\frac{\text { axp }}{\text { SP }}$ \\
\hline 2014 & $2500-25-0-25-2500$ & I GS-ONE & 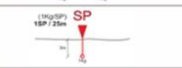 \\
\hline \multirow{3}{*}{2017} & $2000-20-0-20-4000$ & $1^{2}$ SG-5 & tos \\
\hline & $3000-20-0-20-3000$ & $f^{2}, \overrightarrow{S G-5}$ & $4 !$ \\
\hline & $3000-20-0-20-3000$ & $p^{2}$ SG-5 & $\int_{1}^{S P_{1}}=\left.\right|_{n} ^{S P_{2}}$ \\
\hline \multirow{2}{*}{2018} & $3000-20-0-20-3000$ & $t^{2}$ SG-5 $p^{2}$ & 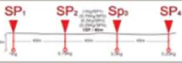 \\
\hline & $3000-20-0-20-3000$ & $P$ SG-5 & 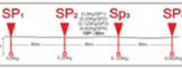 \\
\hline
\end{tabular}

Figure 1: Evolution of parameters of ENEVA during seismic campaigns (2009-2018)

\section{Method}

The seismic data acquired in the Parnaíba Basin show strong coherent noise from surface waves. Also, it is intensely affected by environmental noise, with intense transit of people, animals, vehicles and power transmission lines, highlighted in Figure 2, wind and periods of intense rain. To avoid environmental noise, an appropriate operational schedule for periods of less disturbance is adopted, as a good practice for attenuation. In addition, as illustrated in figure 4 , strict control of the coupling of charges and receivers to the terrain is made.

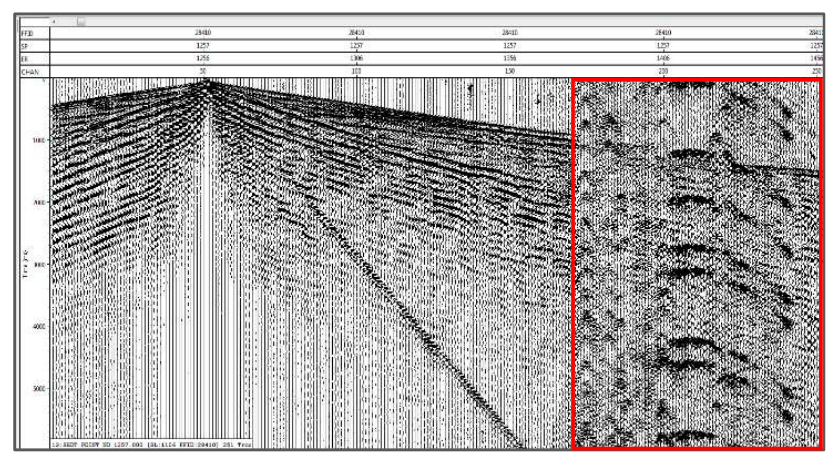

Figure 2: Seismogram shows a shot point with random noise from vehicles nearby.

In order to evaluate the quality of the seismic data by increasing the sampling of both reflections and coherent noise, tests were performed reducing the interval between receiving stations in three $2 \mathrm{D}$ seismic lines in different regions of Eneva's concession areas in the Parnaíba Basin (Figure 3), State of Maranhão, as show in Figure 3, during the company's last seismic acquisition campaign, called 0375_2D_NOVA_IORQUE Program.

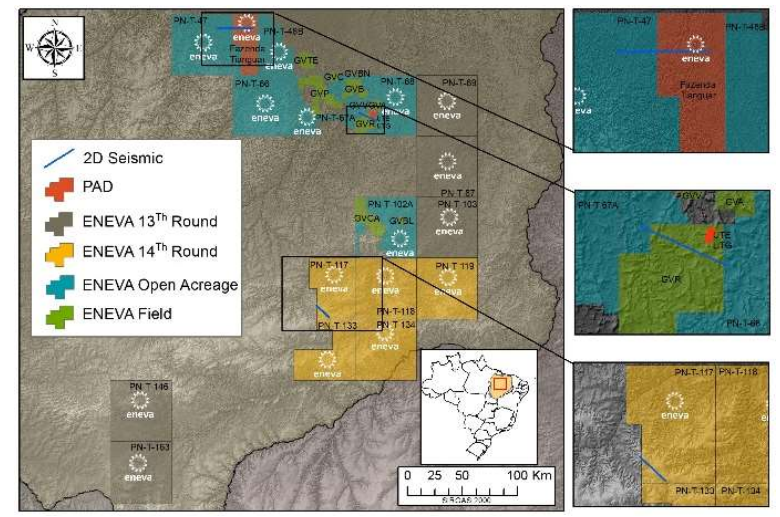

Figure 3: Eneva assets in Parnaiba Basin, and location of the tests performed on 2D seismic lines.

The standard spread used in this seismic campaign was 5000-25-0-25-5000 m, using 400 active channels with IRS and SPI of $25 \mathrm{~m}$ and $50 \mathrm{~m}$, respectively, containing a single charge per shot point, planted at a depth of $2.5 \mathrm{~m}$ with the weights that varied sequentially from $500 \mathrm{~g}, 302 \mathrm{~g}$ and 150 $\mathrm{g}$ along the seismic line (Neto 2021, Figure 4).

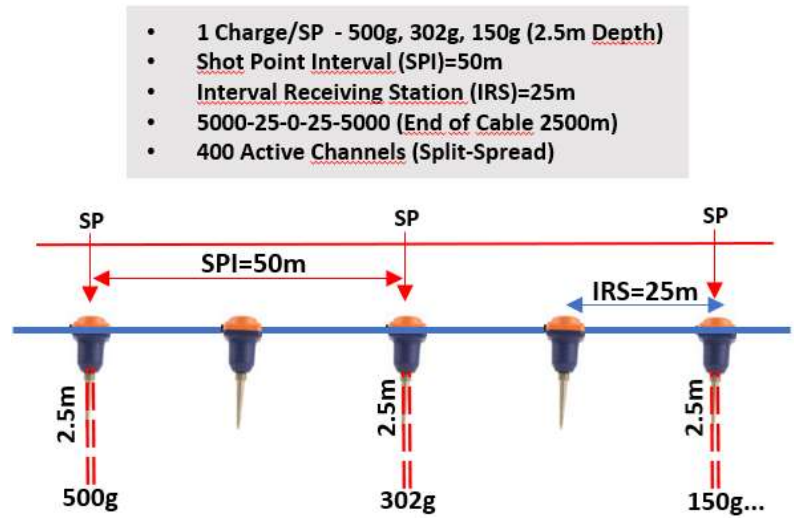

Figure 4: Array of sensors and charges used on 0375_2D_NOVA_IORQUE seismic campaign.

For the tests, the interval between receivers was reduced by half, going from $25 \mathrm{~m}$ to $12.5 \mathrm{~m}$, doubling the number of active channels to 800 , keeping the spread and coverage and reducing the CDP's interval to $6.25 \mathrm{~m}$. Figure 5 shows the scattering of seismographic equipment during the execution of field tests. 


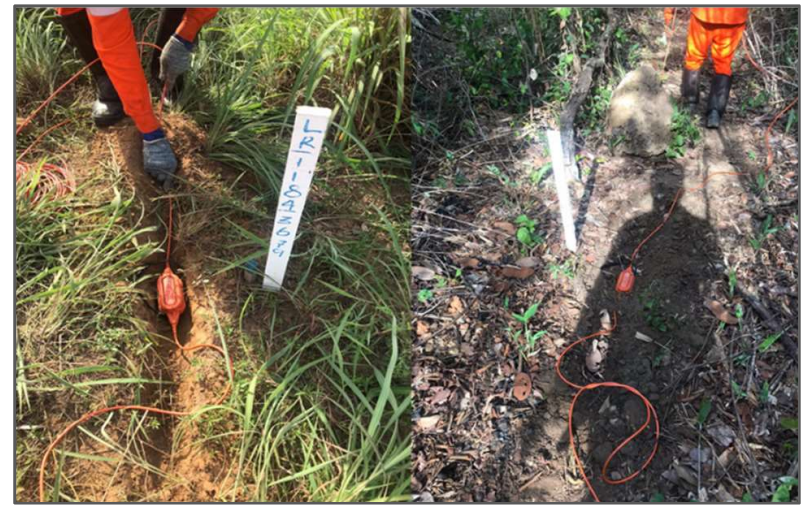

Figure 5: DSU1-508 Accelerometer / Sensor Coupled to the ground from Sismo A team.

The sensor used on this campaign was Sercel's DSU1508 , as show in the technical specification in figure 6 , being a single digital sensor. It differs in that it is an accelerometer, whose recording range varies between the frequencies from $0.25 \mathrm{~Hz}$ to $800 \mathrm{~Hz}$, in addition, the DSU1508 , stands out for its ease of operation, integrated with a digital converter already present in its architecture, the sensor is transported and planted more efficiently, compared to a network of geophones with 6 units for example.

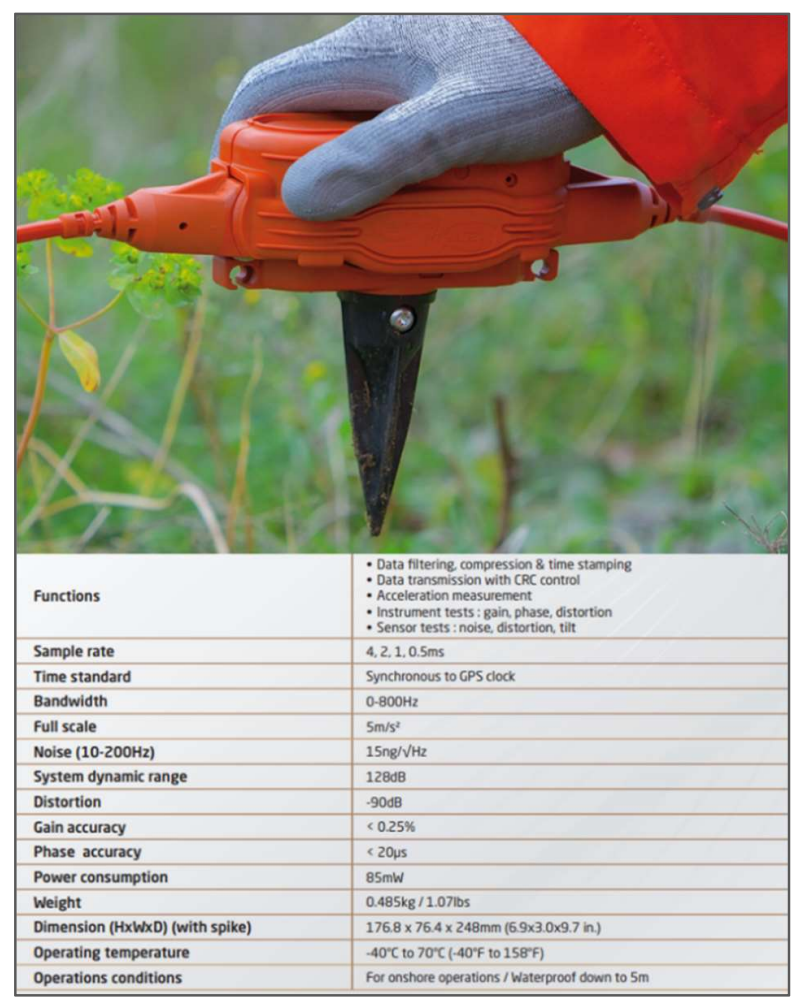

Figure 6: Parameters of DSU1-508 (SERCEL, 2021)

In order to compare, the seismic processing crew simply generated two versions of the test of 2D seismic lines. One version with all receivers (12.5 $\mathrm{m} \mathrm{IRS}$ ) and another version removing half of receivers, returning the configuration of the seismic campaign ( $25 \mathrm{~m}$ IRS).
The seismic processing workflow used to compare both versions of $2 \mathrm{D}$ seismic lines was the same.

In practical terms, effectively in the field, there was an increase in work for topography and seismography teams. The operational effort can be significant with the duplication of the sensors planted, the topography team had to raise the double of coordinates and apply the picket (mark) in the raised point. The seismography team, which is normally divided between Sismo A, responsible for spreading the material in the field and recording the seismic data, and Sismo B, responsible for collecting the material and forwarding it to the next section to be recorded, also increased in the demand for work.

\section{Results}

The results obtained by reducing the IRS in the same spread, confirm that better sampling of signal and noise in seismic acquisition, reduces the alias effect (Figures 7 and 8), contributing with seismic processing crew in its challenge of improving the signal / noise ratio and obtaining a better-quality seismic session.

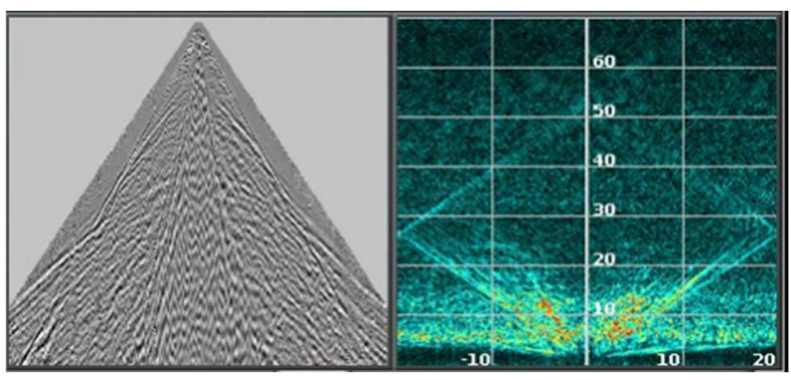

Figure 7: Seismogram and FK spectrum for IRS=25m showing the alias effect.

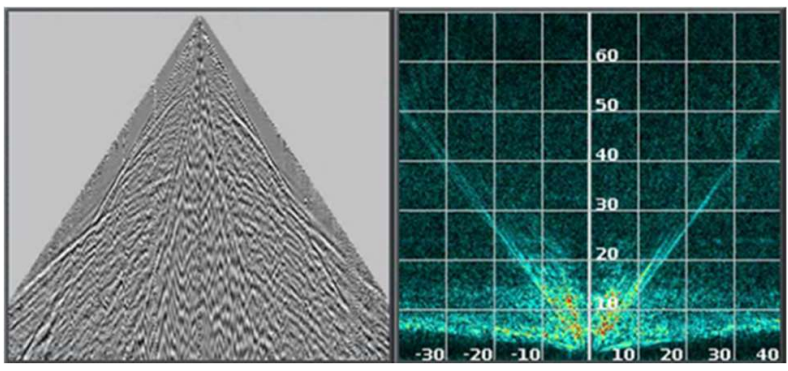

Figure 8: Seismogram and FK spectrum for IRS $=12.5 \mathrm{~m}$

The FK spectrum in Figure 7 shows the alias effect that occurred on IRS $=25 \mathrm{~m}$ version. Due to the lower wave number, the spectral signature of direct waves and ground roll, for example, invades the region of the spectrum corresponding to the reflections, making it impossible to separate these events.

In another example, with the higher wave number observed in the FK spectrum in figure 8 , caused by the better sampling (IRS $=12.5 \mathrm{~m})$, we have a decrease in the alias effect and the signature of undesirable events interfere less in the signal region of the spectrum. The seismogram also shows clearer reflections. 
As an example, figures 9 and 10 show the section of one of the seismic lines processed for the $25 \mathrm{~m}$ IRS, while figures 11 and 12 show the section the same seismic line with the $12.5 \mathrm{~m}$ IRS. When comparing the two sections, relevant post stacking differences are observed. The 12.5 IRS section shows the improved continuity and resolution of the main reflectors. In addition, the seismic section with the stacking of records with 800 active channels suffers less interference from environmental noises and the alias effect (falsification in the seismic data), contributing to a better definition of deeper reflectors.

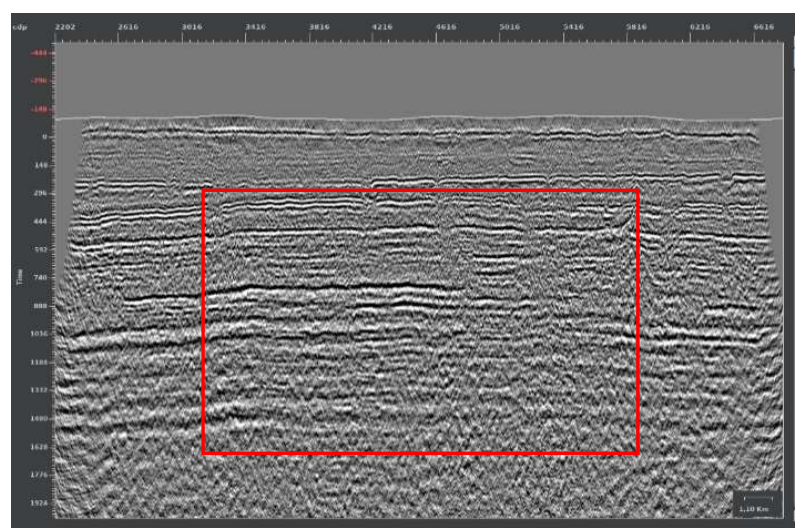

Figure 9: Post stack seismic section with IRS=25m (400 active channels)

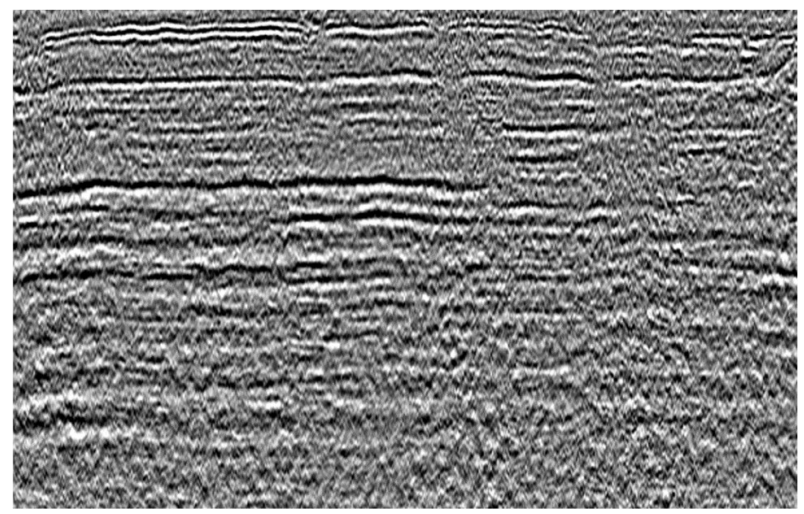

Figure 10: Zoom section with IRS=25m (400 active channels)

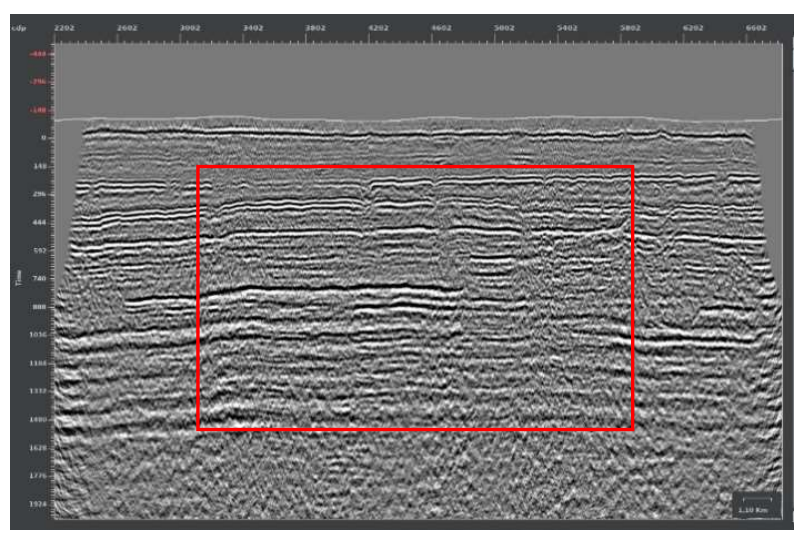

Figure 11: Post stack seismic section with IRS=12,5m (800 active channels)

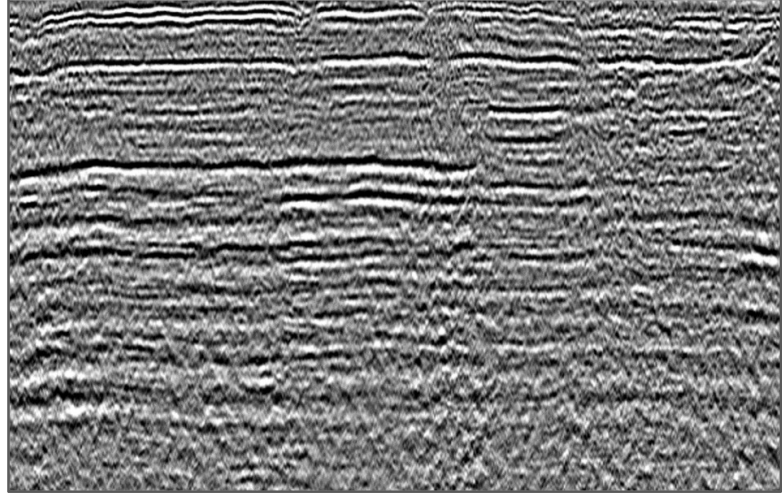

Figure 12: Zoom section with IRS $=12.5 \mathrm{~m}$ ( 800 active channels)

\section{Conclusions}

Due to the challenges inherent in onshore seismic acquisition operations, the cost benefit ratio for choosing a modus operandi, parameters or equipment will always be in focus. However, the latest seismic acquisitions in the Parnaíba basin have proven to be efficient, not only resulting in new discoveries, but also breaking parameterization paradigms.

It's important to highlight that the seismographic equipment and the parameterization of the seismic program influence the quality of the acquired data, which is fundamental for the processing and interpretation of the seismic section, as well as to the costs of providing acquisition services.

Therefore, the search for improvements in seismic acquisition must be incessant, from parameter tests and the use of new technologies, such as accelerometers or wireless and nodal systems, acting in advance in the planning of the campaigns, in order to obtain the best possible seismic data, as well as to make the costs for the company operation feasible.

\section{Acknowledgments}

We would like to thank Wellfield for carrying out the services provision in the acquisition of seismic data, CPGEO for the excellent work of seismic processing, SERCEL for the support in the use of new technology (accelerometers) and finally to ENEVA for encouraging research and fostering the Brazilian onshore seismic acquisition industry.

\section{References}

ANCELME, R. L. Introduction to the seismic method. National Laboratory for Scientific Computing (LNCC), 2015.

ARAÚJO, D. B. de. Parnaíba Basin: Geological Summary and Sectors on Offer. 14th Round of Oil and Gas Tenders. Rio de Janeiro: ANP - SDB, 2017.

ENEVA. Our businesses: Exploration and production. Available at: https://eneva.com.br/nossos- 
negocios/exploracao-e-producao/\#. Accessed on: March 21 st. 2021.

MICHELON, D. RIBEIRO, R. B. CALDEIRA, J. MIRANDA, F. S. GRANDTO, E. SIEDSCHLAG, C. SCHOTS, H. 2D Seismic Acquisition Multi-Load Integrated in Stacking. SBGF Bulletin - 16th International Congress of the Brazilian Geophysical. n. 110. p. 28-31. Rio de Janeiro: Brazilian Society of Geophysics, 2020.

NATIONAL ORGANIZATION OF THE PETROLEUM INDUSTRY (ONIP); NATIONAL OBSERVATORY (ON). Situation of Terrestrial Seismic in Brazil - ONIPGEO Project. Rio de Janeiro: 2004. Preparation of the publication Bacoccoli Associate Consultants.

SANTOS, B. A. Terrestrial 3D seismic acquisition design optimization using mixed base algorithm for inversion and target-oriented illumination. Salvador: UFBA, 2018.

SERCEL. Overview DSU1-508 Sercel. Available at: https://www.sercel.com/products/Pages/DSU1-508.aspx Accessed at: 22nd of March. 2021.

AMERICAN ASSOCIATION OF PETROLEUM GEOLOGISTS (AAPG), AAPG Explorer Magazine, Riding Brazil's Onshore Wave, Tusla: jun. 2021 